\title{
IMPLANTAÇÃO DE MODO DE CONTROLE AUTOMÁTICO PARA O SISTEMA DE INJEÇÃO DE GÁS NATURAL NAS CALDEIRAS DA CENTRAL TERMOELÉTRICA 2 NA CSN*
}

Milson de Andrade Júnior ${ }^{1}$ Marcelo Duque da Silva ${ }^{2}$ André Luis de Oliveira ${ }^{3}$ Diogo Theodoro Lago ${ }^{4}$

\section{Resumo}

A Central Termoelétrica número 2 (CTE\#2) possui três caldeiras de alta pressão que utilizam principalmente os combustíveis residuais dos processos siderúrgicos, com destaque para o gás de alto-forno (GAF), o qual está disponível em grande volume e com baixo custo. Como o GAF possui baixo valor calorífico, ele é enriquecido em duas misturadoras com gás de aciaria (GLD) e na ausência ou limitação deste, com gás natural (GN). A partir de 2014, devido a problemas com o gasômetro de GLD, passou-se a utilizar o GN com frequência para fazer o enriquecimento do GAF, o que gerava significativo impacto no custo do vapor devido o alto custo do GN. O sistema de injeção de GN nas misturadoras era controlado de forma manual e praticamente não acompanhava as variações no poder calorífico $(\mathrm{PCI})$ do GAF. Percebeu-se que seria possível implementar um sistema de controle para as injeções que levasse em consideração o $\mathrm{PCl}$ do $\mathrm{GAF}$, reduzindo o consumo de $\mathrm{GN}$ quando o $\mathrm{PCl}$ estivesse mais alto e aumentando o consumo quando o $\mathrm{PCl}$ estivesse mais baixo. Após a implementação deste sistema houve uma significativa redução no consumo médio de gás natural para enriquecimento do gás de alto-forno na CTE\#2.

Palavras-chave: Caldeiras; Misturadora; Gás Natural

\section{IMPLANTATION OF AUTOMATIC CONTROL MODE TO THE NATURAL GAS INJECTION SYSTEM AT THE BOILERS OF THE CSN THERMOELECTRIC PLANT 2 Abstract}

The Central Thermoelectric number 2 (CTE\#2) has three high pressure boilers that use mainly the residual fuel of the steelmaking processes, particularly the blast furnace gas (BFG), which is available in high volume and at low cost. As the BFG has a low calorific value, it is enriched in two mixers with steelworks gas (LDG) and in the lack or limitation of this, with natural gas (NG). From 2014, due to problems with the gasometer of LDG, it started to use the NG frequently to do the enrichment of BFG, which generated significant impact on the cost of steam due to the high cost of NG. The NG injection system in the mixers was controlled manually and practically did not follow the variations in heating value (LHV) of the BFG. It was felt that it would be possible to implement a control system for the injections that to consider the LHV of the BFG, reducing consumption of NG when the LHV was higher and increasing consumption when the LHV was lower. After the implementation of this system, there was a significant reduction in medium consumption of natural gas for enrichment of the blast furnace gas in CTE\#2.

Keywords: Boilers; Mixer; Natural Gas

1 Engenheiro Eletricista, Engenheiro de Manutenção, Gerência de Geração de Energéticos, Companhia Siderúrgica Nacional, Volta Redonda, Rio de Janeiro, Brasil.

2 Técnico em Eletrotécnica, Supervisor de Operação, Gerência de Geração de Energéticos, Companhia Siderúrgica Nacional, Volta Redonda, Rio de Janeiro, Brasil.

3 Engenheiro Eletricista, Engenheiro Especialista, Gerência de Geração de Energéticos, Companhia Siderúrgica Nacional, Volta Redonda, Rio de Janeiro, Brasil.

4 Engenheiro de produção, Engenheiro de Processo, Gerência de Geração de Energéticos, Companhia Siderúrgica Nacional, Volta Redonda, Rio de Janeiro, Brasil. 


\section{INTRODUÇÃO}

A Central Termoelétrica número 2 (CTE\#2) da CSN desempenha um importante papel nas utilidades da Usina Presidente Vargas (UPV), sendo responsável pela geração de cerca de $60 \%$ da energia elétrica consumida na usina, pelo fornecimento de ar soprado para o Alto-Forno número 2 e pelo fornecimento de vapor de processo para a UPV. A CTE\#2 é composta por três caldeiras, dois turbo geradores e dois turbo sopradores. Na figura 1 é mostrado o fluxograma do processo.

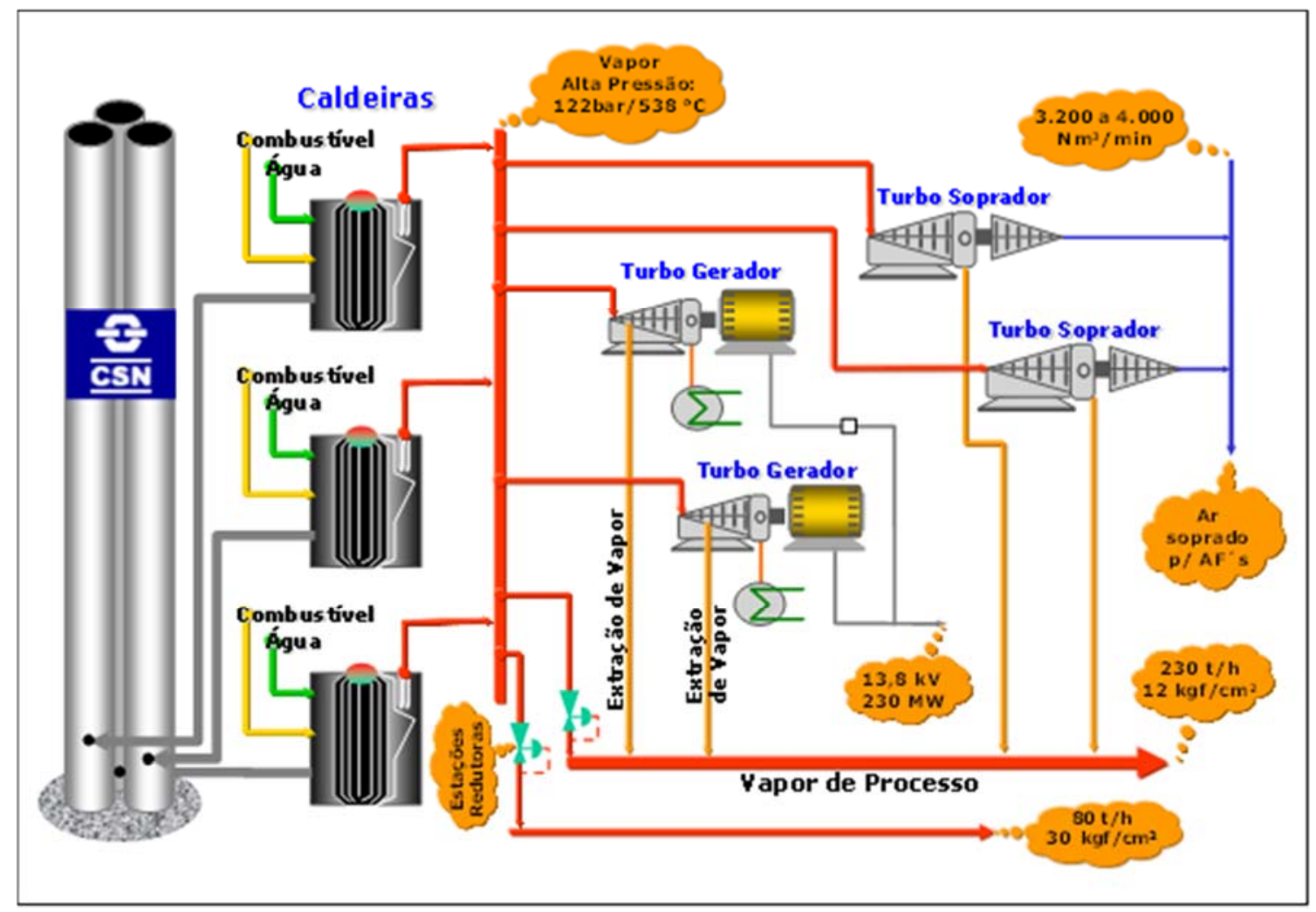

Figura 1 - Fluxograma do processo da CTE\#2

O vapor da CTE\#2 é produzido em três caldeiras de alta pressão do tipo aquatubulares com capacidade total de produção de vapor de $1000 \mathrm{~T} / \mathrm{h}$. Estas caldeiras são denominadas como CAP's 81,82 e 83. Cada caldeira possui 10 queimadores distribuídos em 3 níveis.

No nível inferior ou nível 10 é queimado gás de alto-forno. No nível intermediário ou nível 20 podem ser queimados gás natural, oléo BPF e alcatrão. No nível superior ou nível 30 podem ser queimados gás de coqueria, gás natural, oléo BPF e alcatrão.

De todos os combustíveis utilizados nas caldeiras, o gás de alto-forno é combustível principal devido ao grande volume disponível e por possuir baixíssimo custo. Entretanto, o GAF possui um poder calorífico baixo e que pode sofrer significativas variações de acordo com o processo dos altos-fornos. Para este combustível siderúrgico ser utilizado nas caldeiras da CTE\#2 sem comprometer a segurança operacional é necessário que o mesmo seja enriquecido para garantir um poder calorífico mínimo e mais estável. O enriquecimento do GAF é feito com gás de aciaria e gás natural através de duas misturadoras. O gás natural somente é utilizado neste processo quando existe corte ou limitação de GLD devido ao alto custo deste combustível. O fluxograma atual deste sistema pode ser visto na figura 2 . 


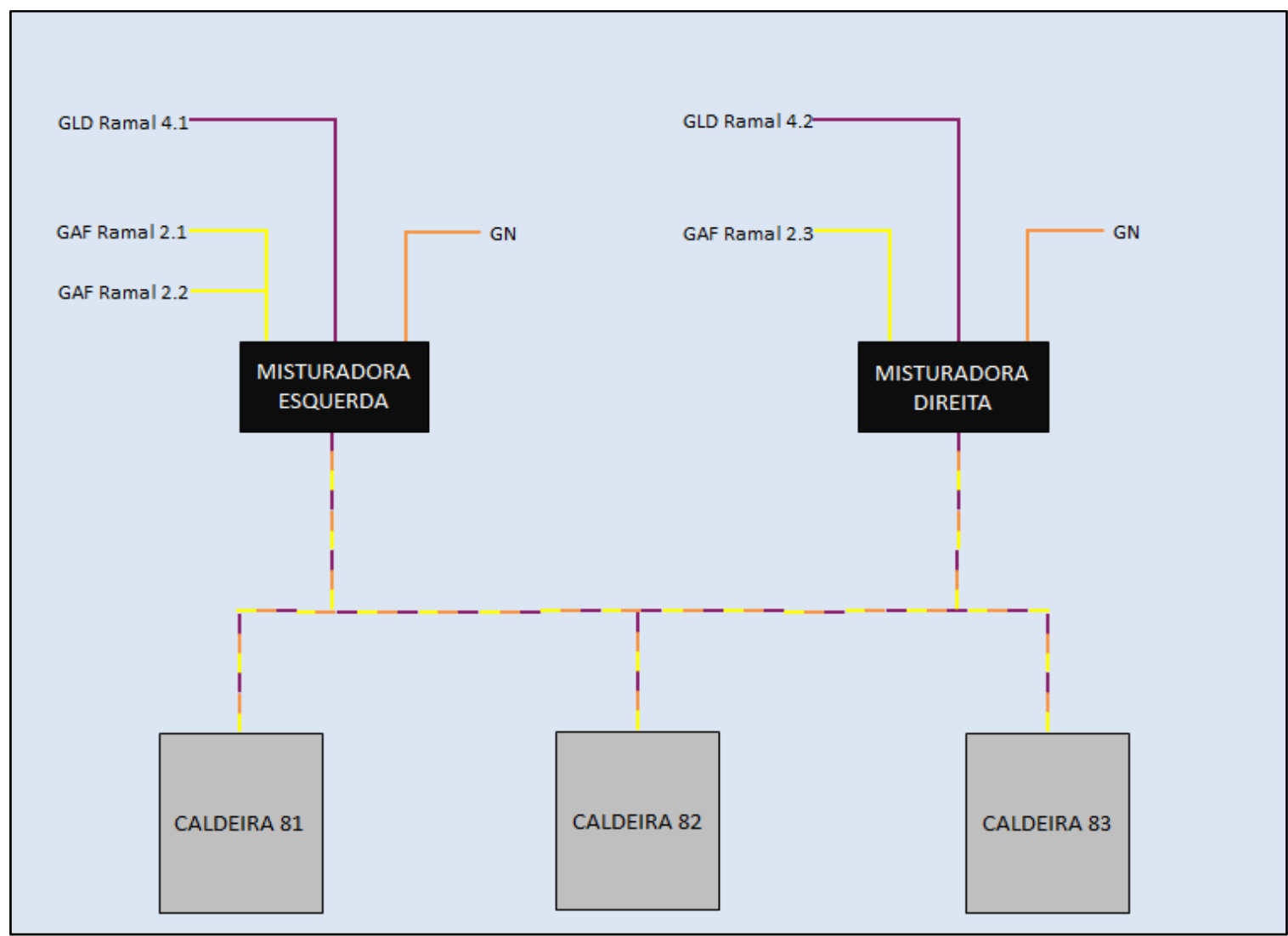

Figura 2 - Fluxograma do sistema de enriquecimento do gás de alto forno

Além do gás natural e gás de aciaria, existe a possibilidade de utilização futura de gás de coqueria dessulfurado (GCO-D) para enriquecimento do gás de alto-forno. Na figura 3 é mostrada uma foto da misturadora esquerda onde é possível visualizar todos os combustíveis envolvidos.

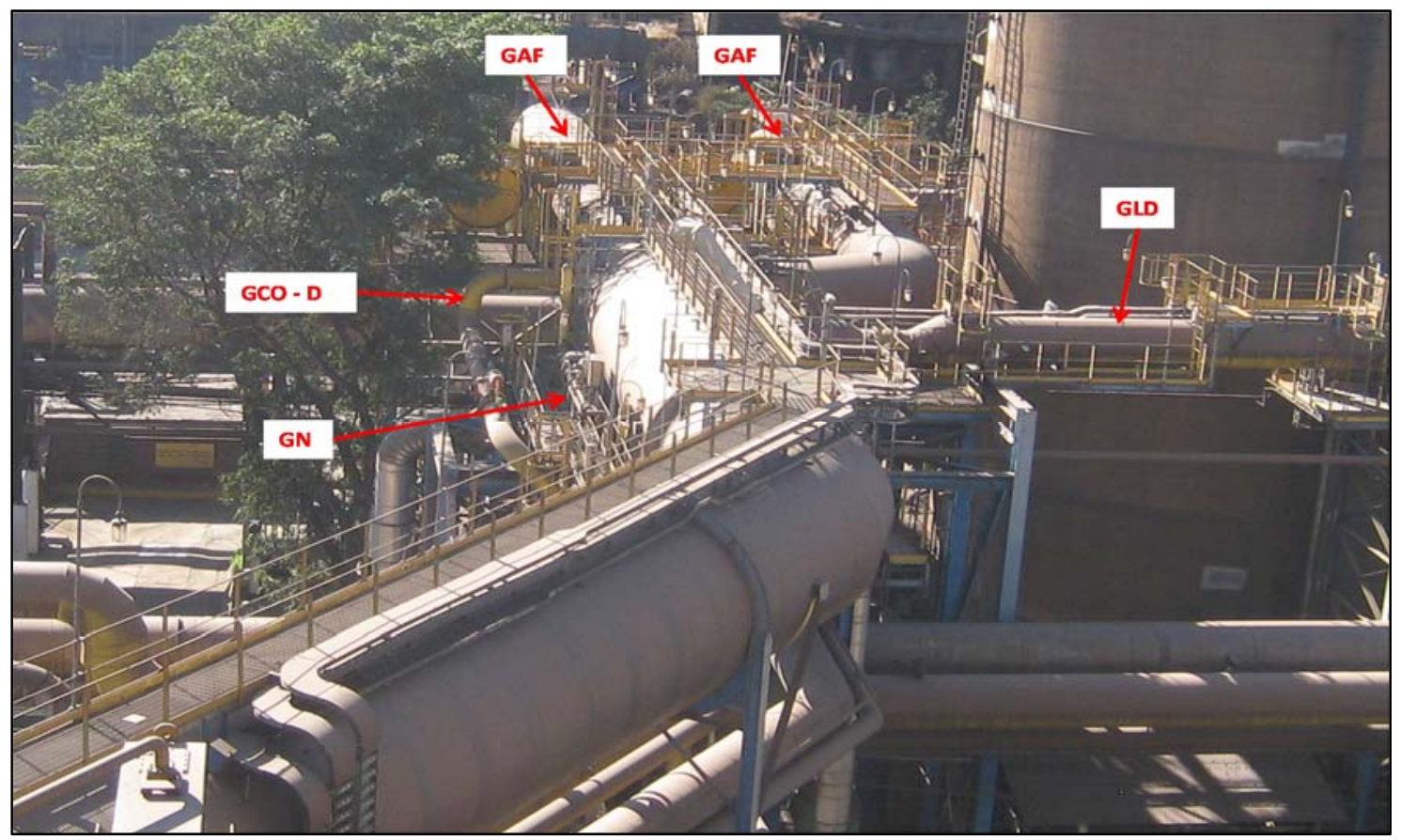

Figura 3 - Foto da misturadora esquerda 


\subsection{SISTEMA DE INJEÇÃO DE GÁS NATURAL}

Chama-se de injeção de gás natural o sistema de enriquecimento do gás de altoforno através da utilização de gás natural. Cada misturadora possui um sistema de injeção de gás natural, o qual é composto por válvula controladora, válvula de bloqueio e medidores de vazão, pressão e temperatura. Na figura 4 é mostrada uma foto da misturada esquerda com destaque para o sistema de injeção de gás natural.

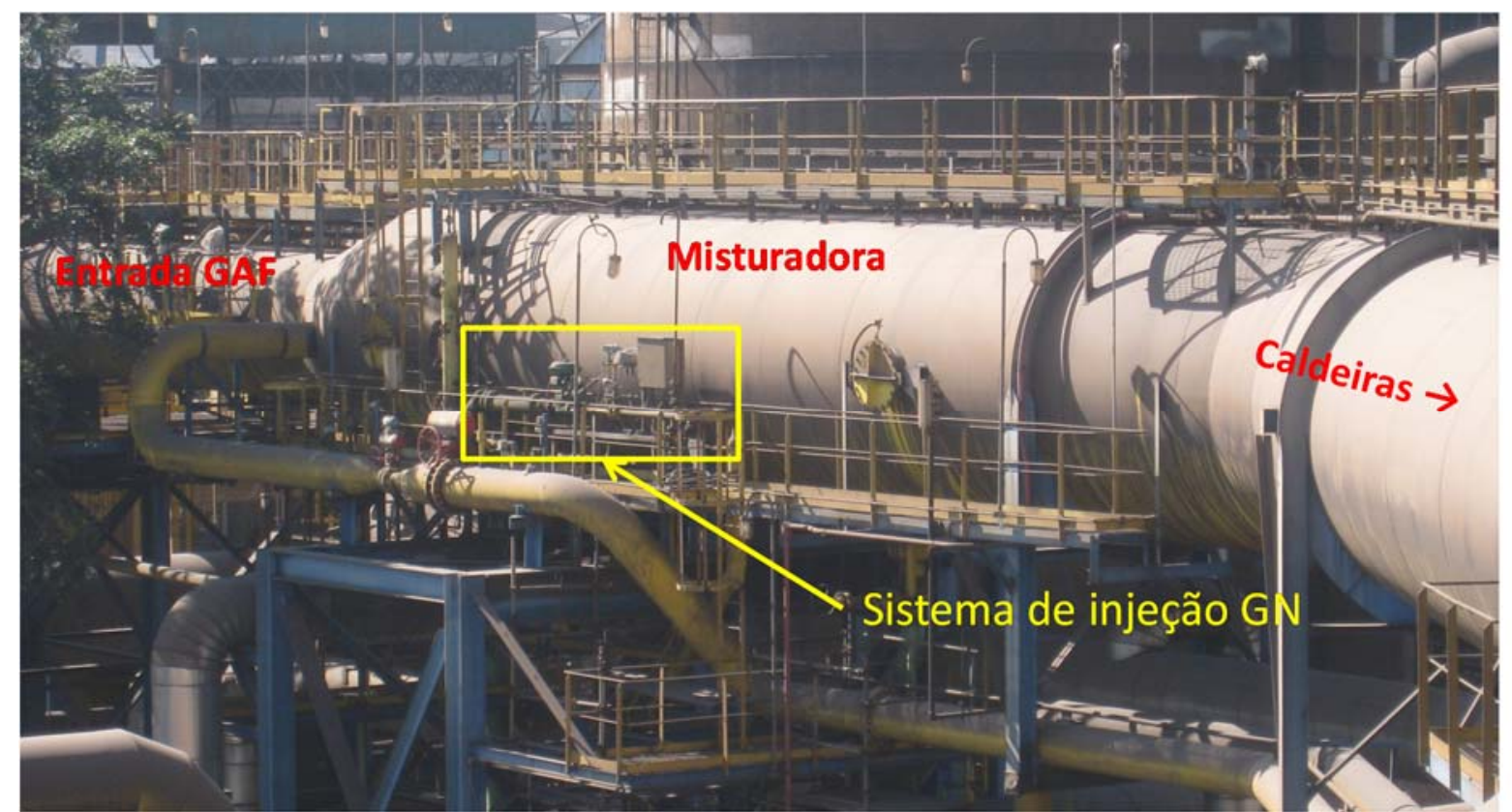

Figura 4 - Foto da misturadora esquerda com destaque para o sistema de injeção de gás natural

\subsection{HISTÓRICO}

Quando havia limitação ou corte de gás de aciaria, deveriam ser consumidos 2,5 $\mathrm{dam}^{3} /$ hora de gás natural nas injeções, conforme procedimento operacional PP502840. O ajuste do consumo era feito de maneira manual e era independente do poder calorífico instantâneo do gás de alto forno. Devido as constantes variações no $\mathrm{PCl}$ do GAF, se tornava impossível um controle manual das injeções de gás natural. Com isso, o que se praticava na falta do GLD, era um consumo de GN que variava entre 2,2 e 2,5 $\mathrm{dam}^{3} /$ hora.

Em 2013, o consumo médio de gás natural nas injeções foi de 0,82 dam $^{3} /$ hora.

Em 2014, pode-se dividir o consumo em dois momentos: de janeiro até o dia 24 de agosto, o consumo médio ficou em $1,13 \mathrm{dam}^{3} /$ hora. O maior consumo em relação ao ano anterior se explica por problemas na distribuição do gás de aciaria, com destaque para uma parada de 58 dias do gasómetro de GLD entre os meses de junho e julho para manutenção. A partir do dia 25 de agosto de 2014, este combustível ficou indisponível para utilização na CTE\#2, devido à nova parada do gasômetro de GLD. Desta vez, sem previsão de retorno. Todo o volume gerado foi direcionado para queima no bleeder. Com a indisponibilidade do gás de aciaria, houve um incremento significativo no consumo de gás natural para enriquecimento do gás de alto-forno. O consumo médio de GN subiu para 2,29 dam³/hora.

Os gráficos de consumo médio de gás natural nas injeções nos anos de 2013 e 2014 são mostrados nas figuras 5 e 6 respectivamente. 


\section{3}

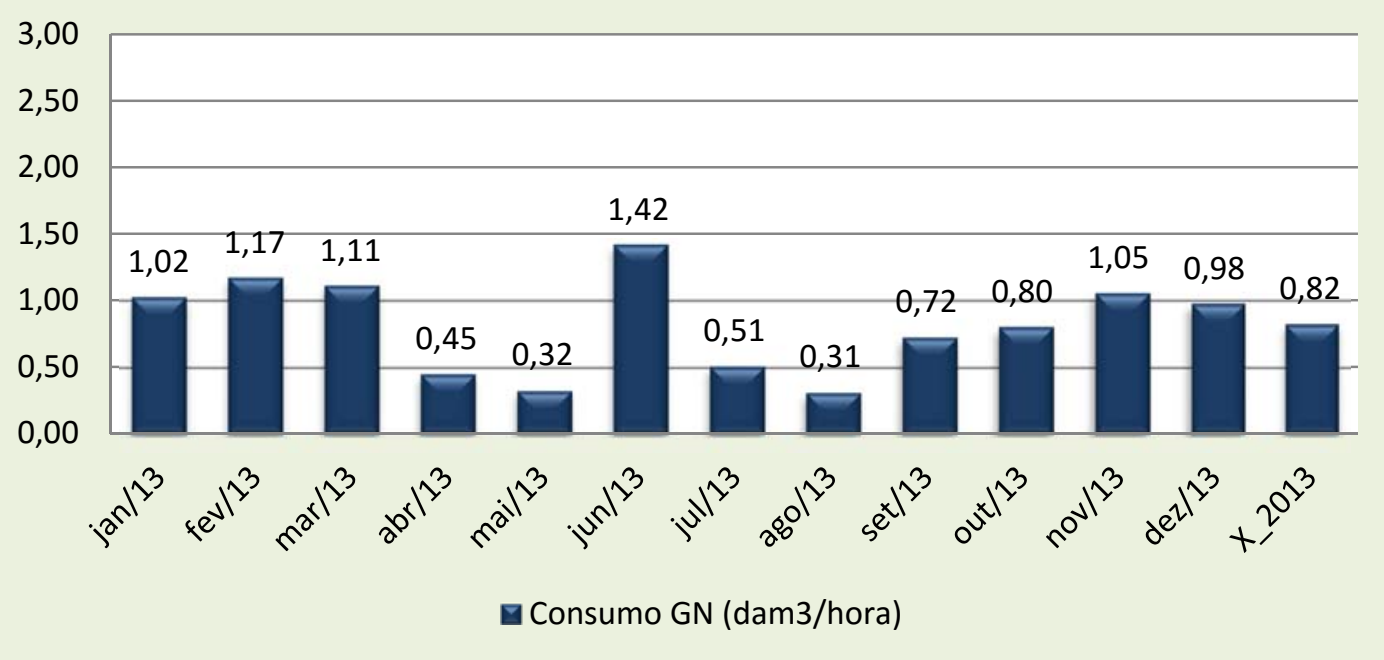

Figura 5 - Gráfico do consumo de gás natural nas injeções em 2013

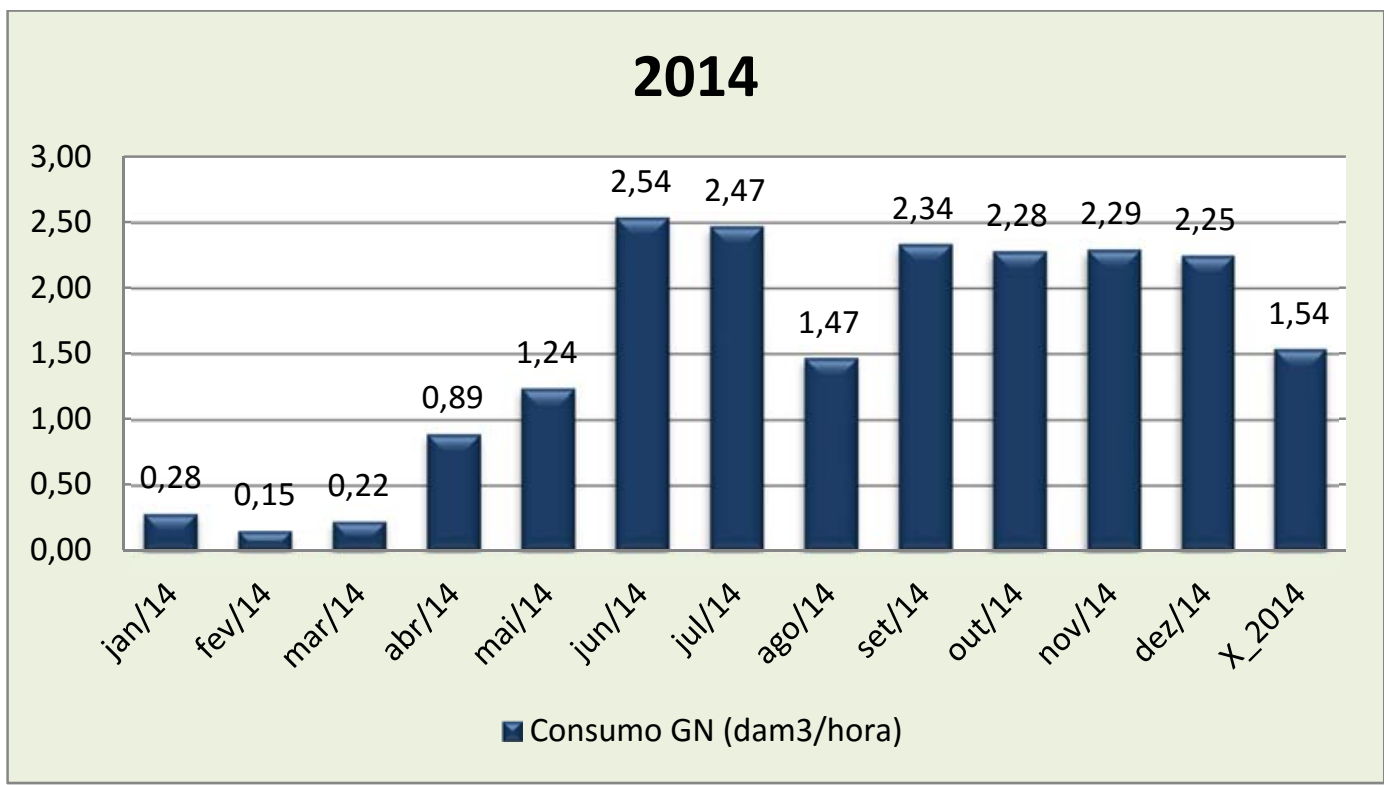

Figura 6 - Gráfico do consumo de gás natural nas injeções em 2014

Com os problemas do gasômetro de GLD, começaram as discussões e avaliações para a implantação de um modo de controle automático nas injeções de gás natural que funcionasse em função do $\mathrm{PCl}$ do GAF, de forma a reduzir o seu consumo e consequentemente o custo do vapor gerado na CTE\#2.

\section{MATERIAIS E MÉTODOS}

Para desenvolvimento deste trabalho foi avaliado o projeto das caldeiras e as características dos combustíveis utilizados na mistura do nível 10. Sabe-se que o $\mathrm{PCl}$ do GAF varia entre 700 e $900 \mathrm{kcal} / \mathrm{Nm}^{3}$ em condições normais de processo. $\mathrm{O}$ $\mathrm{PCl}$ do combustível queimado no nível 10 das caldeiras deve ficar entre 800 e 1150 $\mathrm{kcal} / \mathrm{Nm}^{3}$ por características de projeto dos queimadores deste nível.

No início do estudo para desenvolvimento deste trabalho, constatou-se que o $\mathrm{PCl}$ médio do GAF estava ficando acima de $800 \mathrm{kcal} / \mathrm{Nm}^{3}$, o qual é o valor mínimo para 
queima segura nos queimadores das caldeiras da CTE\#2. Dessa forma, percebeuse que com um controle automático seria possível trabalhar com as injeções de gás natural reduzidas ou até mesmo fechadas em determinados momentos de acordo com o set point da mistura a ser determinado.

Foi desenvolvido um projeto para implantar um modo de controle automático para as injeções de gás natural em função do $\mathrm{PCl}$ medido do gás de alto forno. O projeto consistia nos seguintes itens:

- Desenvolvimento de nova lógica de controle a ser implementada no PLC contemplando todas as proteções possíveis para o processo;

- Calibração dos instrumentos já existentes que passariam a ser utilizados na nova malha de controle (calorímetros e transmissores);

- Definição do valor de set point para o PCl da mistura.

A lógica de controle foi desenvolvida pelos engenheiros de automação da gerência de geração de energéticos. Foram desenvolvidos dois modos de operação: modo de controle de $\mathrm{PCl}$ e modo de controle de vazão.

$\mathrm{O}$ modo de controle de $\mathrm{PCl}$ é um controle em malha fechada, onde é definido um valor de set point para o $\mathrm{PCl}$ da mistura de combustíveis do nível 10 . O sistema compara o valor de set point com o valor do $\mathrm{PCl}$ calculado da mistura em tempo real e atua nas válvulas controladoras de gás natural de cada misturadora para atingir e manter valor de set point. O PCl calculado é uma média ponderada que leva em consideração os valores de vazão e $\mathrm{PCl}$ de cada combustível que entra na mistura. $\mathrm{O} \mathrm{PCl}$ do GN é considerado constante, enquanto o do GAF é variável e é medido pelos calorímetros. Em caso de falha nos calorímetros, o sistema automaticamente muda de controle de PCl para controle de vazão assumindo o set point de vazão que pode ser definido pelo operador. O modo de controle de vazão também é um controle em malha fechada que foi implantado neste projeto e apenas é utilizado quando existe algum tipo de falha nas medições dos calorímetros.

Nas figuras 7 e 8 é mostrado o fluxograma de funcionamento do sistema de controle automático das injeções de gás natural. As duas primeiras ações (ajustar valor de set point e colocar sistema em automático) são realizadas manualmente pelo operador. O restante é feito automaticamente pelo sistema de controle. Por se tratar de controle em malha fechada, o programa ao chegar ao último passo sempre retorna a primeira verificação (status dos calorímetros), enquanto estiver em automático. 


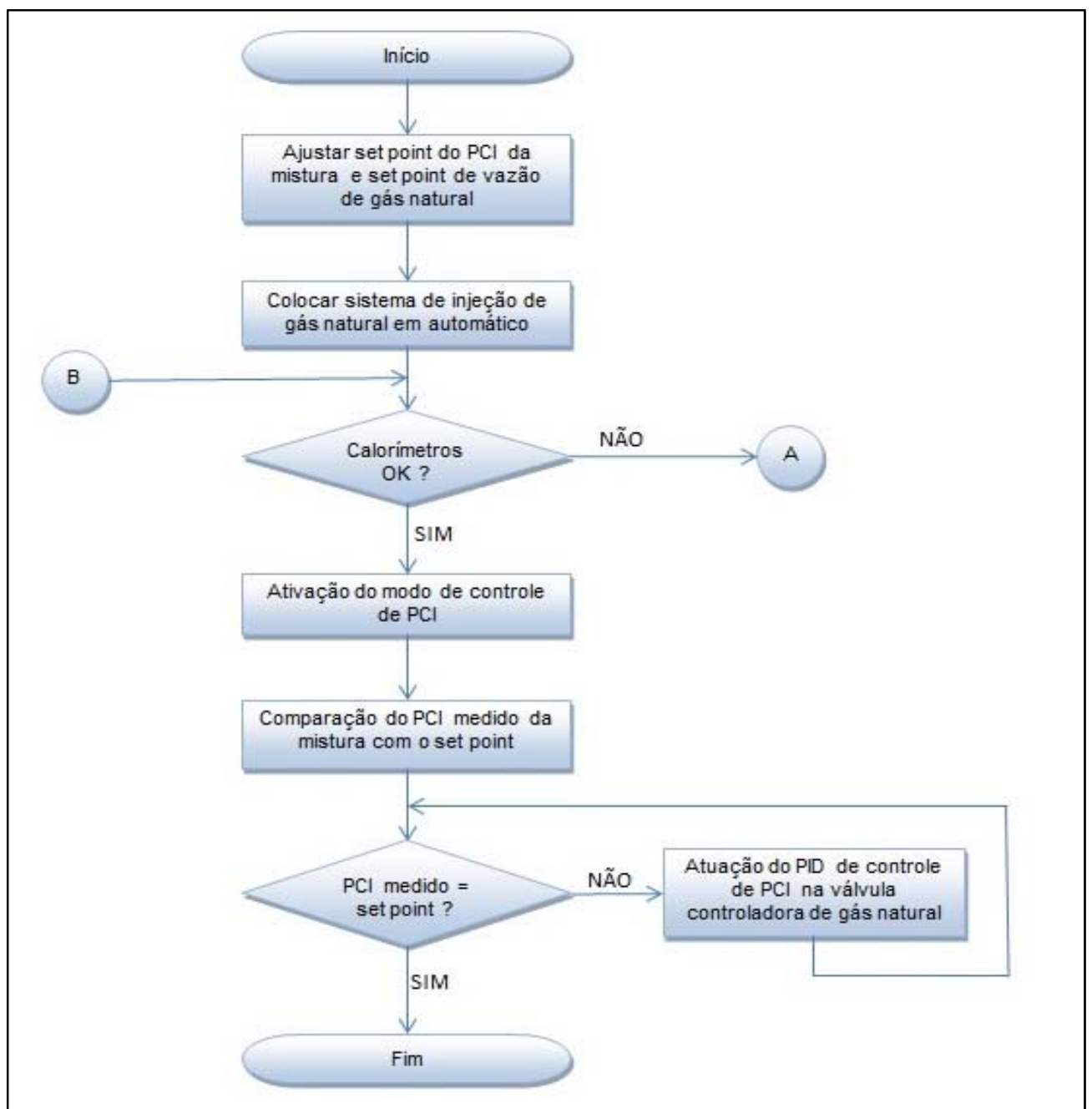

Figura 7 - Fluxograma do sistema de controle das injeções de gás natural - Parte 1

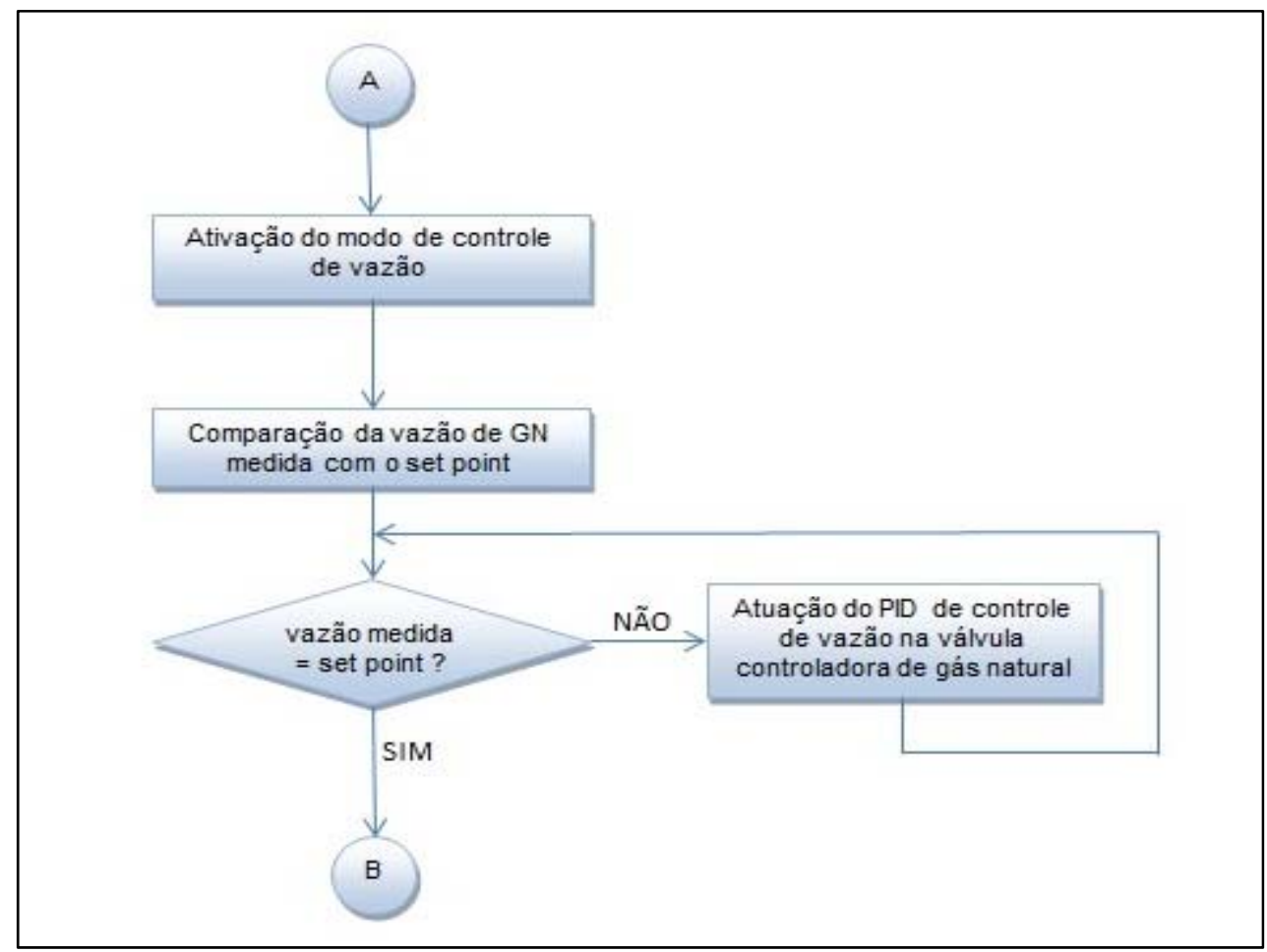

Figura 8 - Fluxograma do sistema de controle das injeções de gás natural - Parte 2 
Aproveitou-se os instrumentos que eram utilizados apenas para medição para fazer a função de controle. Para isto foi necessário realizar a calibração dos mesmos para garantia da confiabilidade do controle.

Para definição do valor ideal de set point para o modo de controle de $\mathrm{PCl}$, foi avaliado o projeto dos queimadores das caldeiras e o processo operacional. Definiuse então o set point do $\mathrm{PCl}$ da mistura em $850 \mathrm{kcal} / \mathrm{Nm}^{3}$ como valor inicial para testar o sistema implantado. Operou-se com este set point de janeiro a julho de 2015. No final de julho de 2015 , o valor de set point da mistura foi alterado para 825 $\mathrm{kcal} / \mathrm{Nm}^{3}$.

Os processos de desenvolvimento da lógica de controle, implantação e comissionamento levaram cerca de quatro meses. O sistema foi entregue a operação no dia 12 de janeiro de 2015.

\section{RESULTADOS E DISCUSSÃO}

Foram implementados dois modos de controle automáticos para o sistema de injeção de gás natural nas misturadoras. Na figura 9 é mostrada a tela de operação da misturadora do lado direito. Pode-se visualizar os blocos onde são definidos o set point de $\mathrm{PCl}$ e o set point de vazão para os novos modos de controle.

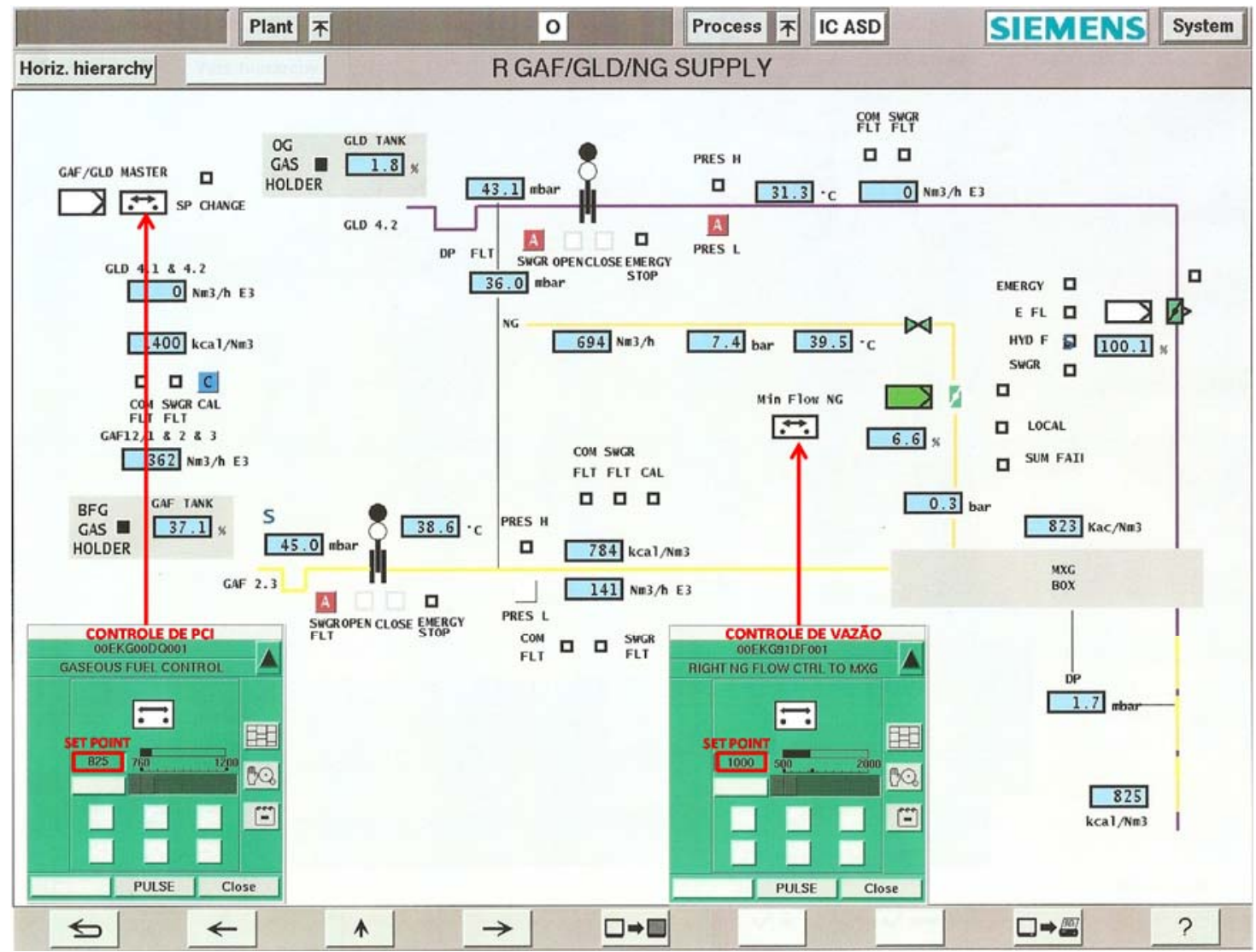

Figura 9 - Tela de operação do sistema de injeção de GN da misturadora lado direito

Do dia 25 de agosto de 2014 (data da parada do gasômetro de GLD) até o dia 11 de janeiro de 2015 (último dia da operação da injeção de GN em manual), o consumo médio de gás natural foi de 2,29 dam³/hora.

Com a operação da injeção de gás natural em automático, o consumo de GN caiu para $0,77 \mathrm{dam}^{3} /$ hora. Isso representa uma redução de $1,53 \mathrm{dam}^{3} /$ hora ou de $66,8 \%$ 
no consumo. Na figura 10 é mostrado o consumo médio de agosto de 2014 a dezembro de 2015. É possível verificar a redução significativa no consumo de gás natural para as injeções a partir de janeiro de 2015.

Em julho de 2015, houve um aumento no consumo de gás natural para as injeções devido ao menor $\mathrm{PCl}$ do gás de alto forno, resultado da redução de produção dos altos-fornos para adequação ao cenário da economia brasileira. Em contrapartida, alterou-se o set point do $\mathrm{PCl}$ da mistura de $850 \mathrm{kcal} / \mathrm{Nm}^{3}$ para $825 \mathrm{kcal} / \mathrm{Nm}^{3}$, visto que havia margem para isto e um estudo para redução deste valor já estava em curso.

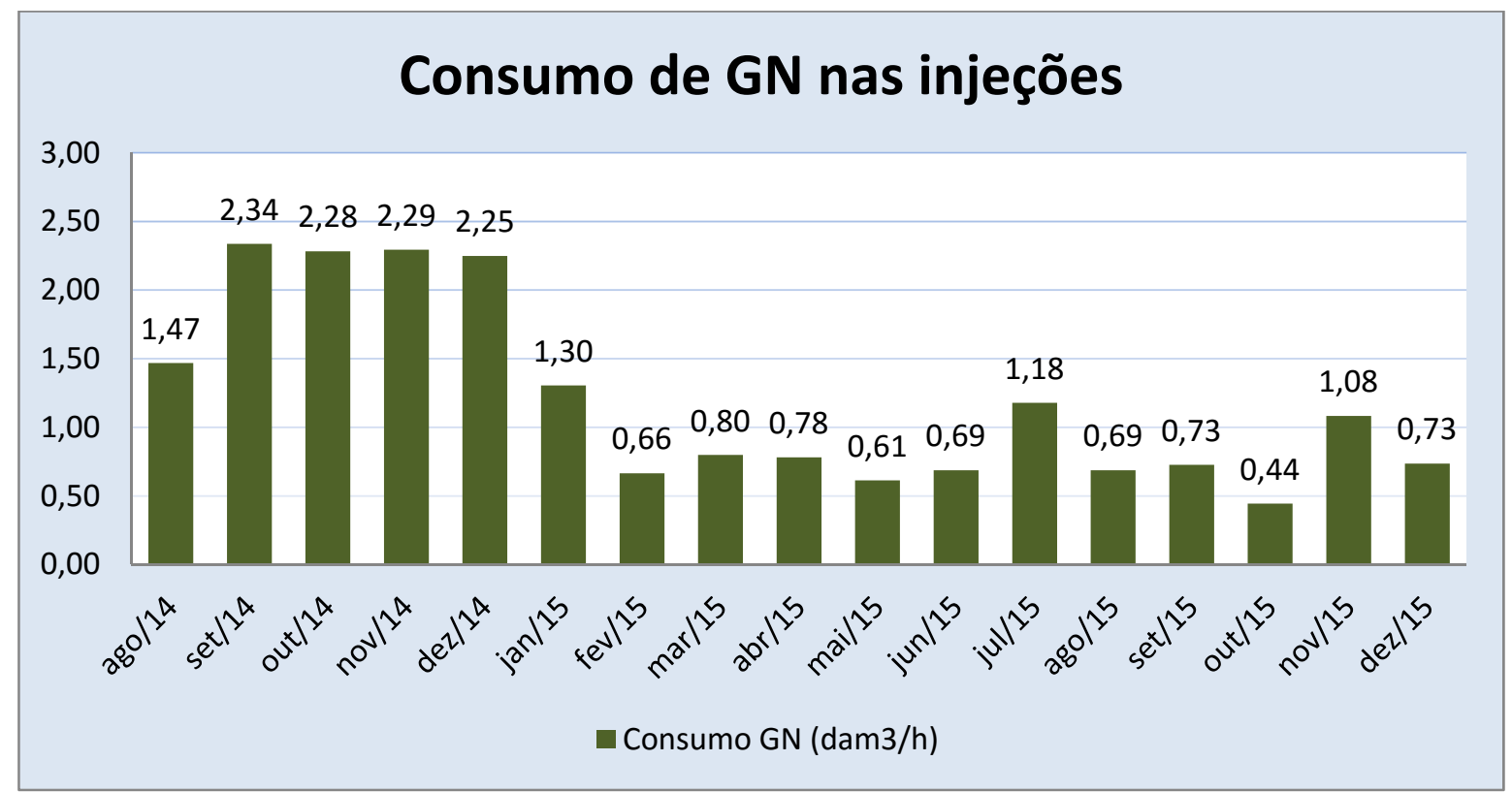

Figura 10 - Gráfico do consumo de gás natural nas injeções

O gás natural representa cerca de $70 \%$ do custo total do vapor. Portanto, qualquer redução no seu consumo tem grande impacto nas utilidades produzidas pela CTE\#2 (vapor de processo, energia elétrica e ar soprado).

Com a redução no consumo de gás natural, houve um melhor aproveitamento do gás de alto forno, cujo excedente é queimado no bleeder. Com isso, este projeto tem um grande impacto positivo no meio ambiente devido à substituição de um combustível fóssil não renovável por um combustível residual do processo siderúrgico.

O gasômetro de GLD retornou de reparo no final de dezembro de 2015.

\subsection{RETORNO FINANCEIRO}

Todo o projeto foi desenvolvido com recursos internos e não houve nenhum custo para a empresa.

Com a implantação do projeto, houve uma redução média de $1,53 \mathrm{dam}^{3} / \mathrm{hora}$ no consumo de gás natural utilizado nas injeções. Isso representa um custo evitado médio de $\mathrm{R} \$ 999.375,02$ por mês com a compra de gás natural em 2015. No gráfico da figura 11 pode-se verificar a economia mês a mês. 


\section{Custo Evitado em 2015}

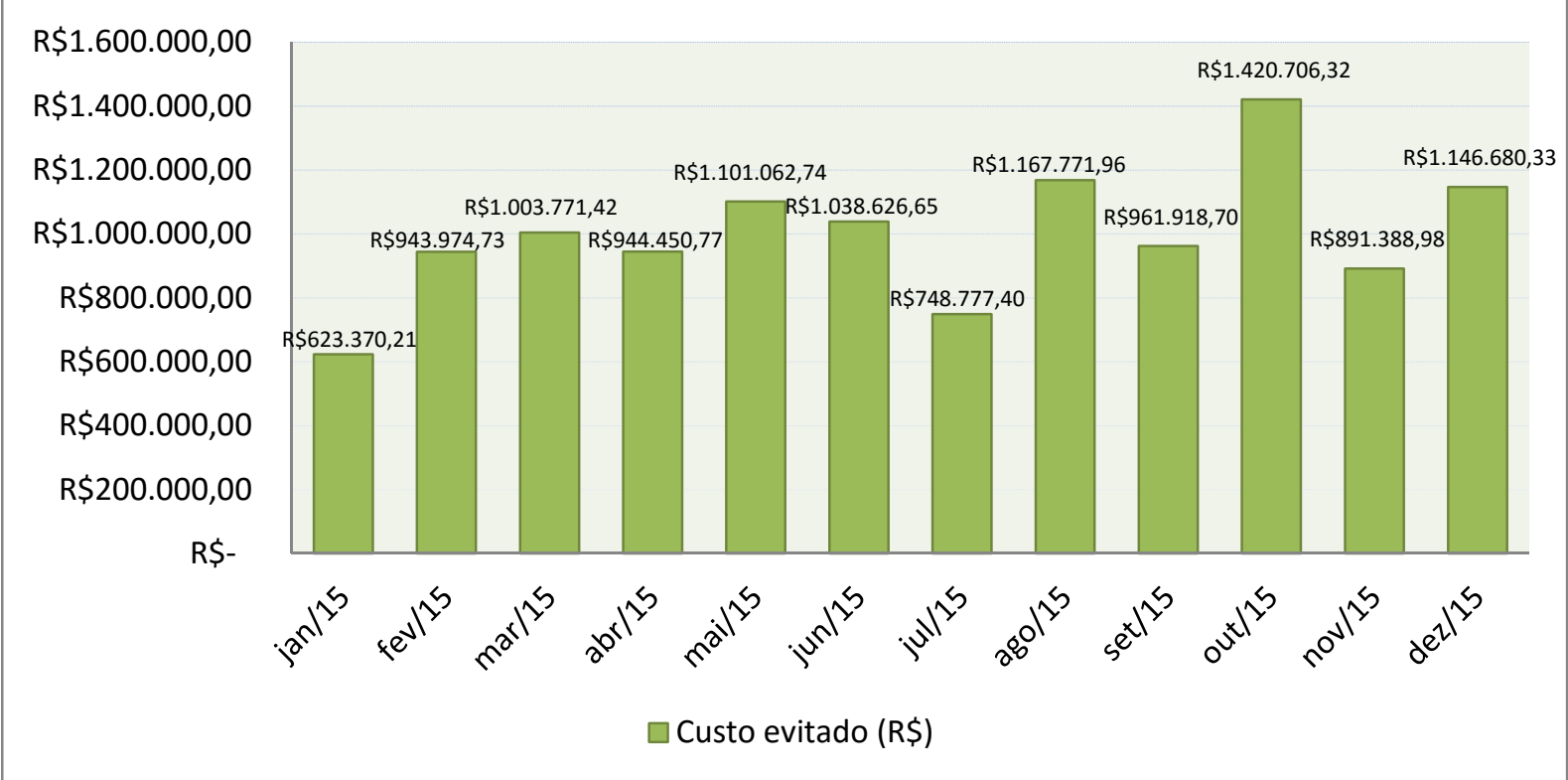

Figura 11 - Gráfico do custo evitado com a compra de gás natural em 2015

O valor total economizado de janeiro a dezembro de 2015 foi de $\mathrm{R} \$ 11.992 .500,20$.

A partir do ano de 2016, mesmo com o retorno em operação do gasômetro de GLD, é esperada uma economia média de $\mathrm{R} \$ 4.746 .000,00$ ao ano no consumo de gás natural utilizado para enriquecimento do gás de alto forno.

Este projeto é classificado pela CSN como um projeto ZIAR (zero investimento e alto retorno).

\section{CONCLUSÃO}

O presente trabalho atingiu os objetivos esperados, pois possibilitou uma significativa redução no consumo de gás natural utilizado para enriquecimento do gás de alto forno, permitindo a empresa aumentar sua competitividade através da redução de custos, além de contribuir com o meio ambiente devido o maior aproveitamento do gás de alto forno e redução da utilização de combustível fóssil não renovável para produção de vapor.

\section{REFERÊNCIA}

1 STEINMÜLLER; Manual de operação das caldeiras; 1998 